\title{
Determining T-cell specificity to understand and treat disease
}

\section{Hadrup, Sine Reker; Newell, Evan W.}

\section{Published in:}

Nature Biomedical Engineering

Link to article, DOI:

10.1038/s41551-017-0143-4

Publication date:

2017

Document Version

Peer reviewed version

Link back to DTU Orbit

Citation (APA):

Hadrup, S. R., \& Newell, E. W. (2017). Determining T-cell specificity to understand and treat disease. Nature Biomedical Engineering, 1(10), 784-795. https://doi.org/10.1038/s41551-017-0143-4

\section{General rights}

Copyright and moral rights for the publications made accessible in the public portal are retained by the authors and/or other copyright owners and it is a condition of accessing publications that users recognise and abide by the legal requirements associated with these rights.

- Users may download and print one copy of any publication from the public portal for the purpose of private study or research.

- You may not further distribute the material or use it for any profit-making activity or commercial gain

- You may freely distribute the URL identifying the publication in the public portal

If you believe that this document breaches copyright please contact us providing details, and we will remove access to the work immediately and investigate your claim. 


\title{
Interrogating T cell specificity to understand disease mechanisms
}

Authors: Sine Reker Hadrup ${ }^{1^{*}}$ and Evan Newell ${ }^{2}$

\author{
${ }^{1}$ Section for Immunology and Vaccinology, Technical University of Denmark \\ ${ }^{2}$ Agency for Science, Technology and Research (A*STAR), Singapore Immunology Network (SIgN), Singapore \\ *correspondence: Sine Reker Hadrup, sirha@vet.dtu.dk
}

Antigen specific T cells and their ability to respond to antigen challenge, is an essential component of our immune system. The in-build complexity and genetic heterogeneity in the antigen recognition molecules, $T$ cell receptors on one site and antigen presentation molecules, Major Histocompatibility Complex (MHC) I and II, on the other site, provides a challenge for immunologist to get full insight and understanding of T cell recognition in health and disease. Here, we discuss the use and development of technologies to gain insight to T cell recognition, and the impact of such knowledge on therapeutic development and disease control. It is evident that applications related to antigen specific T cells or specific T cell receptors have powerful potential in disease eradication. This has been demonstrated in cancer by use of TCR gene modified T cells ${ }^{1,2}$, in infectious disease control through adoptive transfer of virus-specific $\mathrm{T}_{\text {cells }} \mathrm{s}^{3,4}$, and in monitoring responses to tolerizing allergen immunotherapy ${ }^{5,6}$. Additionally, both functional and phenotypic characteristics of antigen specific T cells seem to play a crucial role for the therapeutic efficacy of both adoptive T cell transfer strategies ${ }^{7}$ and vaccination approaches ${ }^{8,9}$. In the era of personalized medicine and with the accumulation of numerous immunotherapeutic strategies being employed, it is becoming increasingly important to understand the T cell mediated responses involved in disease progression or elimination, and to identify biomarkers predictive of response to such therapy - potentially based on experimental analyses of T cell recognition. Thus, effective strategies for simultaneous analyses of such characteristics are highly desirable, and could provide the bases for biomarkers of successful induction of T cell reactivity in various settings.

\section{Identification of $\mathrm{T}$ cell targets in different disease settings}

Antigen recognition by $\mathrm{T}$ cells through the interaction of T cell receptor with peptide-MHC expressed by antigen presenting cells represents a critical step in the initiation of most adaptive immune responses. The fundamental cellular, molecular and biophysical basis for the development and roles of antigen-specific $T$ cells have been elucidated over decades, primarily through analyses of responses to model antigens and through the use of T cell receptor transgenic systems (e.g. 2B4, 5c.c7, OT-1 and 2C) in mice ${ }^{10-14}$. However, because many factors can influence the range and identities of antigens targeted by $\mathrm{T}$ cells during natural infections or diseases $^{15}$, the study of antigen-specific T cell responses in humans is particularly challenging. Even for very well-studied immunological diseases, knowledge of antigenic determinants and the ability to accurately identify relevant antigen-specific T cells are often lacking. Here, we will discuss progress in the study of the antigen-specific $T$ cell response for a range of diseases to highlight the unique challenges that each provide, especially as it relates to the use of methods that allow for direct identification of the relevant antigen-specific cells. Since the first description of multimerized pMHC complexes and their ability to bind and visualize antigen-specific $\mathrm{T}$ cells by flow cytometry ${ }^{16}$, much progress has been made using this or other strategies to identify antigen-specific T cells in various disease settings ${ }^{9,17}$. Throughout this perspective, emphasis is placed on PMHC multimer-based methods. Although they are not ideal for every situation, and not all HLA types are equally suitable for multimer production, they are amenable to multiplexing, which is allowing for an increasingly broad, less biased and more precise view of the antigen-specific T cell response (Figure 1).

\section{$T$ cell recognition in cancer}


In cancer, various proteins that are over -or de-novo expressed in cancer tissues have been described as targets for $\mathrm{T}$ cell recognition. Early studies on $\mathrm{T}$ cell recognition in melanoma patients identified $\mathrm{T}$ cell epitopes among antigens associated with melanin production, such as MART-1, GP100 and Tyrosinase, and later numerous cancer testis (or cancer-germline) were identified as antigenic targets for $\mathrm{T}$ cell recognition across various tumor types ${ }^{18-20}$. Both have led to specific, and in some cases successful therapeutic strategies in the form of vaccination ${ }^{21}$ and adoptive transfer of antigen specific $\mathrm{T}_{\text {cells }}{ }^{1}$. It has been shown that tumor infiltrating lymphocytes from melanoma patients comprises $T$ cells recognizing a range of these antigens, but also that a substantial part of the immune reaction against tumors cannot be described by recognition of these shared tumor antigens ${ }^{22,23}$. More recently, extensive focus has been given to describe $T$ cell recognition of epitopes derived from genetic alterations in tumors, as these sequences are completely foreign to the immune system, hence the term neoepitopes, and at the same time cancer-specific, they in principle form ideal targets for antigen specific targeting of cancer. Several lines of evidence show the importance of such neoantigens in tumor eradication following immune therapeutic strategies ${ }^{24-27}$. However, although mutational load and predicted number of neoepitopes provides strong correlates of clinical efficacy of immunotherapy, it has been challenging to detect $T$ cells recognizing such neoepitopes in large numbers. Neoepitope specific T cells can be detected across different cancer types ${ }^{25,28-39}$. Tumor foreignness, seems to be a major driver for the efficacy of checkpoint inhibition therapy ${ }^{25,40,41}$, and while foreignness can have many flavors, the genetic alterations are easily mapped even at a personalized level through next-generation-sequencing (NGS), and T cell recognition against tumor specific mutations has been identified in many different cancer types ${ }^{25,28-35}$. However, there is still a huge gap in our understanding of neoepitope recognition in cancer, which should be filled for neoepitope-specific targeting to fully meet its expected therapeutic potential $\left.\right|^{27,42}$.

Profiling epitope-specific recognition in cancer is challenging based on the nature of cancer development and the co-evolution of cancer cells under immunological surveillance. a) Cancer cells are highly heterogeneous, both within a given cancer lesson, among cancer patients with the same diagnosis, and across different tumor types ${ }^{43}$. As such, the potential antigen repertoire is huge, and to a large extend personalized. Such levels of complexity are challenging to encompass even with newly developed multiplex $T$ cell detection technologies ${ }^{33}$. b) Tumor-reactive T cells are often functionally compromised due to immunosuppressive signals mediated by the tumor. Consequently, such T cells may be difficult to culture and assess in functional assays $^{44}$. c) Tumor-reactive $T$ cells recognizing self-antigens most often comprise $T$ cells having escaped central tolerance mechanism. Such T cells would be likely to express TCRs with relatively low affinity for their cognate $\mathrm{pMHC}$ recognition motif or recognize peptides with a very low MHC affinity. Together, these characteristics make it difficult to obtain sufficient TCR pMHC engagement and to generate stable pMHC reagents for T cell assessment. d) Finally tumor reactive T cells are most often of low frequency, which hence further challenge the detection.

\section{$T$ cell recognition in the context of infectious disease}

In infectious diseases, detection and characterization of antigen specific T cells recognizing common viruses has provided important insights to T cell immunology. It is evident, that some viruses seem to partly hijack our immune system by occupying large parts our T cell repertoire. It has been shown that CMV-reactivity T cells may comprise more than $10 \%$ of our bodies T cells in CMV seropositive individuals ${ }^{45,46}$. Since CMV is a common and chronic virus $(>80 \% \text { at age of } 30)^{47}$, T cell reactivity to this virus can have a great impact on immunological ageing and the ability to respond to foreign antigens ${ }^{48,49}$. In CMV seronegative individuals, other chronic viruses seem to take up great fractions of the T cell repertoire, but yet not as dramatically as is observed for CMV. Thus, CMV infection should be taken into account as a possible confounder in any immune therapeutic strategy, and may be used as a biomarker for responsiveness in certain cases. As an example of their therapeutic potential, virus specific T cells have been successfully characterized, in vitro selected and expanded 
for adoptive transfer strategies, which especially in transplanted patients, can clear otherwise life-threatening infections ${ }^{3}$.

Virus specific T cells are in general terms easier to detect than T cells in other contexts such as cancer responsive or otherwise autoreactive T cells. In studies of T cell responses to viral infection, there is a predefined antigen repertoire encoded by the virus genome, and virus responsive T cells are often present in detectable frequencies following infections. For chronic viral infections, such $T$ cells are detectable throughout life. Studying virus specific T cells has further led to a groundbreaking understanding of T cell development in response to both acute and chronic antigen exposure ${ }^{50-52}$.

\section{Challenges for studies of $T$ cell responses directed at bacteria or viruses with large genomes}

Although many of the best characterized T cell epitopes are derived from viruses with large genomes such as EBV or CMV, unbiased screens using multiplex approaches would be particularly challenging for such pathogens. Thus, these epitopes have so far been identified through more conventional T cell epitope mapping strategies using large cell numbers and/or expanded T cell lines to narrow down antigens with peptide libraries. Large screens using enormous peptide libraries, as illustrated for $\mathrm{CMV}^{53}$, have also been very informative in understanding the breadth of $T$ cell responses in these instances. Similarly large screens have also been performed to identify T cell epitopes in the context of mycobacterium tuberculosis (mTB) infection ${ }^{54}$. However, typically for such pathogens with large genomes such as $\mathrm{mTB}$, subsets of proteins are targeted based on prior knowledge about their relative immunogenicity ${ }^{55}$ and in this case, the use of peptide-MHC multimers (tetramer guided epitope mapping) have also been shown to be useful ${ }^{56}$. Along these lines, in the study of a rotavirus, with a moderately sized genome, large scale screening using combinatorial encoded heavy metal tagged pMHC tetramers was used to identify new rotavirus epitopes and to compare the profiles of these cells between donors and tissues. In parallel, further analysis of numerous EBV-specific T cell populations showed distinct phenotypes of T cells specific for latency vs. Iytic cycle EBV antigens ${ }^{57}$. Thus, although peptide MHC multimer based approaches are not necessarily the best place to start when studying bacterial or viral infections with pathogens that have large genomes, multiplex approaches can still be leveraged in these settings.

\section{Studies and modulation of self and allergen-specific T cells in autoimmunity and allergy}

More recently, the interrogation of antigen specific T cells has reached the autoimmune and allergy field. In allergy, peptide-MHC tetramers and an approach called tetramer-guided epitope mapping (TGEM) has been used to identify numerous useful MHC class II restricted antigens ${ }^{58,59}$. This information has then been leveraged in several investigations into the roles of CD4+ T cells in modulating the response to various allergens such as nuts, house dust mites and pollen ${ }^{6,60,61}$. Most autoimmune diseases, including Type I Diabetes (T1D), Reumatoid arthritis (RA) and multiple sclerosis (MS) has genetic associations to the MHC gene family, especially HLA class II molecules, certainly indicating an HLA class II/CD4 T cell involvement in the pathophysiology. But CD8 $\mathrm{T}$ cell recognition has been shown to be involved as well ${ }^{62-64}$. Although limited established knowledge is available as to what CD4 and CD8 T cells recognize in these diseases, some progress has been made. In T1D it has been shown that insulin, GAD, and proinsulin proteins are targets for T cell recognition, and that the presence of such $T$ cells is associated with disease development ${ }^{65-67}$. In autoimmune diseases the antigens targeted by the immune system may also be modified by post translational modifications (PTM) creating neoepitopes to which there is no immune tolerance. This has been shown in e.g. T1D ${ }^{67,68}$, systemic lupus erythematosus (SLE), rheumatoid arthritis (RA), and multiple sclerosis (MS) ${ }^{64,69,70}$. Studies have shown that prediabetic NOD mice have antibodies and effector T cells that react against citrullinated GPR78 ${ }^{66}$, and additionally, increased T cell reactivity to citrullinated peptides arising from GAD65 was described in T1D subjects $^{65}$. A recent study in T1D, has identified an alternative open reading frame within human insulin mRNA encoding a highly immunogenic polypeptide that is targeted by T cells in T1D patients ${ }^{62}$, similarly a product 
from alternative splicing has been demonstrated as frequently recognized by $T$ cells in cancer ${ }^{71}$. In general, studying $T$ cell recognition in autoimmune diseases is challenging due to the lack of defined antigens, the unpredictable nature of dysfunctional self-tolerance and intrinsic difficulties in HLA class II epitope mapping (See Box 1). Besides diabetes or other diseases where there are some good ideas about the possible targets of T cells auto-aggression, real challenges lie ahead for inflammatory diseases where the targets and roles of $\mathrm{T}$ cell antigen specificity are less well established or may even be triggered without specific antigens involved ${ }^{72}$. Some general aspects of T cell detection challenges in various disease settings are summarized in Table 1.

\section{Challenges in the study of antigen specificity of $C D 4^{+}$helper T cells}

In general, across various diseases settings, CD8 T cells are more frequently studied than CD4 T cells, since the tools available for CD8 T cell analyses and epitope prediction are more robust (further discussed in box 1). This partly relates to the structural differences between $\mathrm{MHC}$ class I and II molecules. MHC class I has a closed conformation, and peptide binding is consequently very restricted in terms of length and anchor positions ${ }^{73}$, allowing for more precise prediction of $\mathrm{MHC}$ I binding properties of a given peptide ${ }^{74}$. On the contrary, $\mathrm{MHC}$ class II molecules have an open conformation allowing the presented peptide to extend the end of the MHC II binding groove. Hence, MHC II peptide binding is less stringent than class I and it is more challenging to describe and predict MHC II peptide binding simply due to the greater flexibility in the system ${ }^{75}$. MHC multimers can be generated for both $\mathrm{MHCI}$ and II, and used for assessment of both CD8 and CD4 T cells. However expression and refolding of MHC II molecules is more demanding than for $\mathrm{MHCI}$ and in most cases requires expression and purification from insect or mammalian cells ${ }^{76}$. Additionally, sufficient binding avidity between pMHC II multimers and CD4 T cells can be difficult to achieve, and this may be partially related to the fact that the CD4 co-receptor provides limited support for the pMHC interactions as compared to the CD8 MHC I interaction ${ }^{77,78}$. This provides additional challenges for $\mathrm{T}$ cell detection technologies, such as fluorescent labelled MHC multimers, to reach sufficient sensitivity and specificity. Finally, widely-used strategies for peptide-exchange of MHC-embedded conditional ligands to generate large libraries of pMHC complexes are so far only developed for MHC class $\mathrm{I}^{79}$. The same holds true for di-peptide mediated peptide exchange ${ }^{80}$ or facilitated refolding strategies ${ }^{81}$. Analogous approaches for MHC class II based on the expression of MHC with an enzymatically (e.g., thrombin) cleavable tethered CLIP peptide do allow for relatively high throughput production of MHC class II multimers, but this approach seems to only be feasible for some MHC class II alleles. HLA-DR and mouse I-E alleles have been used effectively, but this does not seem to work well for HLA-DP, -DQ and mouse I-A alleles ${ }^{82,83}$.

\section{Strategies for dissecting $T$ cell recognition in disease settings}

Interrogation of $T$ cell recognition in a given disease context can either be achieved through direct access to the disease mediating T cells - often T cells infiltrating the diseases tissue ${ }^{20,84}$. These can be analyzed through bulk $\mathrm{T}$ cell expansion, $\mathrm{T}$ cell cloning or $\mathrm{T}$ cell receptor identification and re-expression to examine their peptide recognition potential. Such strategies can be determined as 'the direct immunology approach' where the T cell recognition motif is identified through target cell recognition using CDNA library expression, yeast display ${ }^{85,86}$. or target cells of different origin (Figure 2). Alternatively, when no disease-specific T cells are available, these can be identified through screening of T cell recognition in diseases relevant settings, using a set of predicted antigens selected based in the available pathophysiological knowledge. Numerous T cell epitope mapping strategies have been developed to support this 'indirect immunology approach' (Figure 2) and each has advantages and disadvantages that greatly depend on the disease setting (some are summarized in Table 2). Strategies to map the epitope landscape include (but are not limited to) mass-spectrometry-based sequencing of eluted peptides, NGS based predictions of e.g. mutation-derived neoepitopes and yeast display approaches (Figure 2). Despite ongoing efforts in developing multiplex-approaches, in many instances the range of possible 
antigens that can be screened will be to too large to be examined using synthesized peptides and peptide-MHC multimer libraries. One way to narrow down the candidates is to elute peptides from target cells and use mass spectrometry to sequence these peptides ${ }^{32,87,88}$. Additionally, the potential antigenic repertoire seems to contain a variety of peptides currently not covered by these approaches alone, such as e.g. spliced peptides ${ }^{89,90}$. Thus, a combination of experimental techniques as e.g. mass spectrometry, sequencing analyses, proteasomal digestions, and other experimental strategies addressing peptide processing as well as constantly improved prediction analyses may be necessary to improve the sensitivity for antigen identification.

\section{Detection of antigen specific T cells using soluble-phase MHC multimers}

When candidate target antigens exist or are predicted, MHC-multimer based strategies have evolved to efficiently assess $T$ cell reactivity to large peptide libraries. Three strategies for detection of antigen specific $T$ cells using soluble-phase MHC multimers are frequently used in epitope discovery project and will be in focus here:

1. Fluorescently-labelled combinatorial encoded MHC multimers (flow cytometry):

Two approaches were described in 2009, using combinatorial-encoding of fluorescently labeled MHC multimers. Both approaches take advantage of the assumption that any given $\mathrm{T}$ cell in the cell sample will respond to only one of the pMHC molecules in a given library. Thus, each distinct pMHC multimer can be assigned with a unique dual color code ${ }^{91}$ or multivalent code ${ }^{92}$, which is then used to identify the T cells binding to this particular pMHC molecule. When employing the unique dual color code, any $T$ cell not matching the pre-determined color combinations is considered as non-responsive to the given $\mathrm{pMHC}$ multimer. This strategy provides a low limit of detection $(0.002 \%)$ and an improved distinction between background events and specific pMHC binding T cells, compared to single-color fluorescent labelling approaches. However, both approaches require that peptide sequences with minimal variation are analyzed in separate samples, to avoid cross-recognition between peptides within a given sample. This strategy has so far been used to dissect T cell reactivity against up to 45 different $\mathrm{pMHC}$ complexes in a single sample, but with recent progress in the field of muliticolor flow cytometry this strategy may easily expand to a higher complexity. Novel flow cytometers allow up to 50 parameters to be detected simultaneously, and there is an ongoing effort to characterize and design new fluorescent molecules to match this complexity. However not all fluorochromes has sufficient intensity to be used for tagging of MHC multimer specific T cells. With a hypothesized number of 30 different fluorochromes available for tagging of MHC multimers, the system using dual color codes would allow 420 different $T$ cell specificities to be analyzed in a given samples. Thus, reaching far beyond what has previously been implemented using this strategy - and such complexity will certainly call for computational analyses the flow cytometry data ${ }^{93}$. It should be noted, that despite improved analyses tools and automated compensation matrixes adjusting for spectral overlap between fluorescent molecules, there will be substantial reduction of signal due to spectral overlap in certain channels ${ }^{94}$.

\section{Metal labeled combinatorial encoded MHC multimers using mass cytometry (CyTOF):}

With the emergence of mass cytometry that uses heavy metal ions as tags, there has been a dramatic leap in the number of labels that can be applied in parallel compared with fluorescence flow cytometry

95-97. Combining mass cytometry with combinatorial pMHC tetramer staining using a total of 10 metal labels applied in unique combinations of three labels per MHC multimer, has enabled screening for 109 different antigen-specificities in one sample, while still leaving a substantial number of labels for parallel phenotype and functional analysis of $\mathrm{T}$ cells ${ }^{57}$. Extending this approach with additional metal channels dedicated to $\mathrm{pMHC}$ tetramers and/or using quadruple combinatorial coding, several hundred 
tetramers can be used in parallel, while still retaining $>20$ channels available for profiling of the antigen specific cells (unpublished data). As discussed below, mass cytometry based high-dimensional assessment of $\mathrm{T}$ cell phenotype and function has shown that $\mathrm{T}$ cells derived from human blood and tissues are remarkably diverse in terms of their protein expression profiles ${ }^{98-101}$. This high-resolution perspective of T cell profile is particularly powerful when combined with the ability to discriminate $T$ cells based on antigen specificity. This way, T cells derived from precious tissue such as tumorinfiltrates can be used without expansion to simultaneously screen-for $T$ cells antigen specificity and to deeply profile the antigen-specific cells detected. The disadvantages of mass cytometry as a screening platform includes its low efficiency in cells capture (only $40 \%$ of the acquired cell will be analyzed) and the inability to retrieve these cells after analyses. However, these limitations are slowly improving as better strategies are developed for implementing this technology.

Mass cytometry and the ability to analyze large numbers of proteins at the single cell level together with the development of many new high dimensional data analysis methods have led to a greater appreciation of the complexity of immune cell heterogeneity in both blood and in tissues ${ }^{98-101}$. In particular, it has been used to expose the great extent of functional heterogeneity that $\mathrm{T}$ cells possess in both blood and across tissues, and how this relates to the expression of various other cellular markers such as trafficking receptors ${ }^{102-104}$. Also in various disease settings including mass cytometry is being used to more broadly profile changes in cellular composition over the course of disease ${ }^{105-107}$. Thus, it is clear that T cells are incredibly diverse, especially within tissues, and now the challenge remains to understand how this diversity is related to the antigen-specificities of these cells and how this information can be used to better understand and predict disease outcomes.

\section{DNA-barcode labelled MHC multimers (Cell sorting \& NGS)}

The most recent addition to the immunologist toolbox for detecting $T$ cells based on antigen recognition involves implementation of a new type of label. Instead of using fluorescence or metal labels, we have applied unique DNA barcodes that, when attached to MHC multimers, form specific tags for the given pMHC epitopes ${ }^{33}$. DNA barcodes can be designed with a complexity of up to $10^{10}$ different sequences, each forming a unique $\operatorname{tag}^{108}$. As a result, this strategy is not bound by the number of available labels, which has previously been the most critical limitation for high-throughput detection of antigen-responsive T cells. We have shown that this approach can be applied to screen for more than 1,000 specificities in a single sample. The read-out using this technology is fundamentally different in that it measures the number of pMHC-TCR interactions rather than the number of specific cells. Taking advantage of a common fluorescent label on all pMHC multimers it enables a calculation (fraction of specific reads out of total reads $x$ freq. of sorted cells), that estimate of the frequency of specific $T$ cells in a given sample ${ }^{33}$.

The DNA barcode-based approach offers the advantage that it is less dependent on stringent fluorescent-based separation of multimer positive from multimer negative events. The technology therefore represents an attractive tool for detecting low avidity TCR:pMHC interactions such as shared tumor-associated antigens ${ }^{33}$. Such $\mathrm{T}$ cells are merely detectable based on fluorescent separation due to the limited amount of fluorescent labelled pMHC mutimer binding to their surface. But these T cells can still be specifically determined based on their DNA barcode signal. However, this strategy remains to prove its potential in terms of identifying $T$ cell recognition as correlated to disease progression or response to therapy. The strength for detection of self-antigens may be useful in studying both cancer and autoimmune $\mathrm{T}$ cell recognition. 
Additionally, the nature of the tag form an ideal basis for combining pMHC binding with sequencing approaches as the DNA barcode tag can be amplified and revealed in any sequencing platform upon adaptation.

\section{Other MHC-multimer based approaches}

In parallel to the development of the soluble-phase approaches as described above, a number of plate-bound or matrix strategies has been developed, likewise to increase the capacity of pMHC-based screenings. Proteinbased microarrays have been developed and combined with pMHC-based capturing of T cells - with pMHC mono-or multimers either as the plate-bound protein directly responsible for cell capturing ${ }^{109-115}$ or through specific probes associating PMHC molecules to a given spot on the microarray. However, the spatial separation of T cells may impact the sensitivity of the overall strategy as most such approaches seem to be limited by a low sensitivity and reproducibility compared to existing cytometry based analyses. Matrix-based approaches have been developed for T cell identification. In this method, a set of MHC multimers are split into matrixdefined pools, in such a way that no specific $\mathrm{MHC}$ multimer are present in all pools. Each multimer pool is used to stain an equal number of cell aliquots derived from a given sample. For each pool, TCR $\beta$ sequencing is applied to both the MHC multimer positive and negative populations following cell sorting, and TCR $\beta$ clonotypes enriched within the positive population and uniquely identified in pools carrying a given pMHC molecule are identified and used to reveal the antigen specificities within the sample ${ }^{116}$. A similar approach has been used to identify numerous allergy antigens based on CD4 T cell recognition ${ }^{61,117}$.

\section{Detection of antigen specific $T$ cells based on functional markers}

A number of techniques have been used to determine the functional capacity of antigen specific $T$ cells, and to identify target reactive $T$ cells based on a functional readout. These include primarily measures of cytokine release either by intracellular cytokine staining (ICS) or ELISPOT (Table 2). More recently the staining of surface markers induced by antigen stimulation e.g. CD154 or CD137 has been used to efficiently track antigen responding $T$ cells in selected disease settings. However, this strategy does not provide direct information about the peptide recognition of the responding $T$ cell population it can provide value information about the level of T cell recognition. Ideally, when antigen specific T cells are examined using MHC multimer staining additional functional readout should be provided. However, T cell stimulation leads to TCR internalization and consequently may at least partially impede such combined investigations. Information about functional capacity can be essential to understand the role of $\mathrm{pMHC}$ specific T cells in a given disease settings. For instance, tumor-infiltrating lymphocytes have been described staining with both, wildtype and mutated MHCpeptide-multimer ${ }^{30}$ whereas distinct binding of a defined mutated MHC-peptide-multimer may not necessarily exclude wildtype reactivity ${ }^{32}$. Thus, current technological improvement of large-scale descriptive analyses of T cells by MHC multimer technologies should be followed by investigation of T cell function or role in a defined clinical context. For in-depth and fully validated characterization of T-cell responses, additional testing systems that allow functional analyses, deeper phenotyping and RNAseq are important and may require TCR isolation and transduction experiments.

\section{Future perspectives for understanding antigen recognition}

T-cells may recognize and destroy cells presenting non-self-peptides (epitopes) bound to MHC molecules. This recognition is mediated by the heterodimeric T-cell receptor (TCR). The number of possible distinct TCRs (here $\alpha \beta$ TCRs) generated through genetic recombination, has been estimated at $\sim 10^{15}$ although the number of distinct TCRs in an individual human is probably closer to $10^{7118,119}$. Consequently, T-cell recognition is very complex, designed to match the complexity of intruding pathogens. Adding to the complexity is the genetic 
variation in major histocompatibility complex I (MHC I) loci, resulting in a large diversity in MHC expression among individuals. Although TCRs appear to be highly restricted in terms of HLA-recognition determined by individuals HLA type ${ }^{120,121}$, a given T cell is capable of recognizing multiple antigens. In fact, estimates suggest that each TCR can recognize up to $10^{6}$ different peptide sequences ${ }^{86,122}$. Thus, strategies that allow coverage of both the complexity of the antigen-landscape and the cross-recognition capabilities of a given TCR, could provide novel understanding in terms of the relationship between these two facets. Such information might also provide insight into the relationships between infectious agents and autoimmune reactivity, which has for many years been suspected to play a role in the development of autoimmune diseases.

Future strategies should allow for:

1. Epitope mapping and antigen selection at a genome-wide level

2. Interrogating the naïve T cell repertoire

3. Improved target prediction through TCR profiling

4. T cell recognition patterns beyond distinct antigens

\section{Epitope mapping and antigen selection at a genome-wide level}

The methods currently available to map this complex interaction on a molecular level are poorly matching the diversity in immune recognition. Consequently, immune analyses are currently focusing on a panel of model antigens that only provides information about a few needles in the total immune haystack. The identification of important targets for immune recognition will greatly enhance our ability to combat disease and tissue destruction - therefore technologies are needed that significantly extend state of the art to enable a much more comprehensive assessment of T cell mediated immunity.

Prediction of peptide-MHC affinity has become a valuable tool for predicting peptide presentation ${ }^{123}$, but this is only partly describing the potential immunogenicity. Unbiased analyses of peptide presentation and their ability to mount immune responses is needed to allow prediction including other parameters than MHC binding, which is currently the key component for any such prediction. Characteristics of antigen processing are currently not improving prediction of $\mathrm{pMHC}$ presentation. Recent progress is being made in developing more sensitive mass-spec-based analyses of MHC embedded peptide ${ }^{32,124,125}$. Such strategies, especially when combined with unbiased T cell analyses should significantly improve our ability to predict which peptides will be presented at the cell surface, capable of mounting an immune response.

Improved prediction tools are of particular interest in the field of personalized neoepitope vaccination ${ }^{124,126}$. Neoepitopes are defined based on the patient-specific cancer mutagenome and formulated into a vaccine $e^{42}$. However, most available vaccine platforms allow the combination of 2-20 different epitopes in such vaccine formulation, and hence require precise prediction tools to hit the target. Currently, limited knowledge is available on the immunogenicity of neoepitopes, and consequently prediction algorithms suffer from low sensitivity of prediction ${ }^{127,128}$. More comprehensive and unbiased full mutagenome-wide analyses of T cell recognition would provide valuable data to improve such predictions.

Current tools allow us to screen for $\mathrm{T}$ cell recognition using up to 1000 different $\mathrm{pMHC}$ complexes in a single sample. For DNA barcode labelled MHC multimers, the tagging system may even allow for much more comprehensive screenings. The maximum library size that can be reached and applied for simultaneous screening of $\mathrm{T}$ cell recognition has not yet been established using this strategy. Certainly limitation exist in the ability of a given $\mathrm{T}$ cell to reach all possible $\mathrm{pMHC}$ complexes in the mixture and to avoid unspecific binding 
driven by the CD8 interaction, when pMHC multimer solutions reach very high concentration. Microfluidics systems can likely be applied to assure this balance and hence this strategy may even allow for full peptidomics screening.

Of equal importance is our ability to combine T cell specificity analysis with complex phenotyping and assessment for functional characteristics. This is currently achieved using the CyTOF-based strategy, which may even extend in the future as larger numbers (hundreds are already possible) of pMHC-multimers continue to be integrated into this strategy and as mass cytometry approaches improve in terms of throughput, sensitivity and cellular recovery. Emerging strategies in the field on single cell analyses and index sorting further allow for single cell mRNA expression analyses while protein level of selected parameters can be achieved by flow cytometry ${ }^{129}$. More recent, high-throughput strategies for single cell analyses, such as the drop-seq approach $^{130,131}$ allows for fast and efficient analyses at a single cell level, where antibodies ${ }^{132,133}$ or pMHC molecules $^{33}$ may be DNA barcoded to obtain specific knowledge on protein expression and T cell specificity while maintaining all the mRNA embedded information (Figure 3).

\section{Interrogating the naïve T cell repertoire}

Additionally, as these highly multiplexed T cell detection technologies become increasingly more sensitive, we might reach the ability to interrogate the naïve repertoire, in terms of understanding what naïve T cells from a given individual is capable of responding to ${ }^{134}$. We are not born with equally abilities to fight infections - or risk of developing autoimmune diseases. Such variations can partially be explained by the genetic variations in HLA expression, but certainly our $\mathrm{T}$ cell repertoire plays a central role determining our ability to recognize target cells expressing foreign-or modified antigens, as a consequence of infection or malignant transformation.

However our current tools to interrogate the TCR repertoire is very immature. Novel insight to TCR repertoire recognition could significantly improve our ability to design personalised therapies, not only based on individual expression patterns but also the patient's ability to respond to such antigens as determined by their T cell repertoire. Currently, we have no techniques that allow the interrogation of the naïve T cell repertoire in a comprehensive fashion. It has been shown that the ability to respond to antigen challenge is dependent on the precursor frequency of naïve T cells capable of recognising a given antigen, and that such measure can successfully be incorporated in vaccine design, used for selection of epitopes most likely to raise immune recognition. But, interrogation of naïve precursor $T$ cell frequencies on the individual level is very labour intensive and not feasible for implementation in patient tailored therapies in the current form. The ongoing initiatives to target neoepitopes in cancer through therapeutic vaccination is currently challenged by the weak prediction of neoepitope immunogenicity, and novel tools providing insight to patients $T$ cell repertoire and the ability to respond to certain antigens would significantly increase the chance for selecting effective vaccination targets (epitopes) ${ }^{28}$.

\section{Improved target prediction through TCR profiling}

Despite significant improvement in T cell detection we remain to establish the link between TCR sequence and antigen recognition profiling. Since such interactions are extremely complex, they are expected to be very challenging to predict. This calls for improved computational modulations of the TCR pMHC interaction. Consequently, large libraries of matched-pairs of TCR-epitope specificity are required to achieve sufficient 
insight to TCR-based epitope recognition, enabling such computational modulation and ultimately allow prediction of epitope recognition motif based on TCR sequence. This is a very tall order but some progress is being made ${ }^{135,136}$, and strategies for collection of TCR sequence and antigen specificity at a single cell level becomes increasingly more efficient. In reverse, yeast-display of peptide-MHC libraries are being used to better understand the range of antigens that a given $T$ cell receptor can recognize ${ }^{85}$. Recently, two independent studies demonstrated the feasibility for assessing the peptide recognition motif of a given TCR and predict the diversity the in terms of peptide restriction ${ }^{137,138}$. Such analysis forms a crucial platform to initiate predictions of $\mathrm{pMHC}$ restriction based on TCR sequence. Computational models have been developed that allow prediction antibody epitopes ${ }^{139}$, and success from this field encourage immunologist to believe the TCR-based predictions will be possible eventually Such strategies would provide a whole new dimension to our immunological understanding and our ability to predict $\mathrm{T}$ cell recognition.

\section{$T$ cell recognition patterns beyond distinct antigens}

Finally, more sophisticated tools can lead us to a more complete picture or network structure for how the T cell repertoires works, and how stimulation with certain antigens during infection can potential impact self-antigen recognition through complex cross recognition mechanisms. It requires tools that enable not only a comprehensive screening for distinct $\mathrm{T}$ cell epitopes, but allow for the analyses of related patterns that such $\mathrm{T}$ cell profiles may additionally recognize. This will provide landscapes of T cell recognition patterns associated with distinct epitope recognition. Strong interaction between experimental immunologist and computational experts is required to solve this challenge. The benefit of such $\mathrm{T}$ cell recognition networks, will be an improved understanding of how immune mediated diseases may co-evolve or impact each other, and how vaccine strategies can be tailored to match individual T cell landscapes.

\section{Translation to therapeutic application}

All strategies mentioned above can provide valuable data to determine or predict the $\mathrm{T}$ cell responsiveness to a given therapeutic intervention and hence serve as a biomarker to guide therapeutic decisions, such as patients tailored treatment selection. Dependent on the disease context and HLA types, a patient-specific selection of targets can be essential. The extreme personalized strategy is found in the form of neoepitope vaccinations ${ }^{42}$. Additionally the immunocompetence of patients can be extremely important. Age is one parameter important for immunocompetance ${ }^{140}$, and is has been shown that younger individuals mount stronger immune responses following influenza vacations ${ }^{49}$. But also preexisting immunity provides an important co-factor; as such CMV infection in younger individual has been shown to enhance immune responsiveness to additional infections or vaccination $^{49}$. Also post- or during therapy immune evaluations may guide decision making. For certain therapies the induction of T cell responses is essential to the therapeutic efficacy, and such T cell responses can be measured and may serve as a response to therapy' biomarker allowing for early signs of clinical response to be realized, while non-responding patients may be offered other therapies. Thus such analyses may guide the selection of potential combination to enhance efficacy in the given patient. (Figure 4).

\section{Display items:}

Table 1. Challenges in identifying T cell epitopes in various immunological diseases. 


\begin{tabular}{|c|c|c|c|c|c|}
\hline Disease type & $\begin{array}{l}\text { Source of } \\
\text { antigens }\end{array}$ & $\begin{array}{l}\text { Possible range of } \\
\text { antigens }\end{array}$ & $\begin{array}{l}\text { Types of T } \\
\text { cells involved }\end{array}$ & $\begin{array}{l}\text { Feasibility for } \\
\text { epitope } \\
\text { discovery using } \\
\text { pMHC } \\
\text { multimers }\end{array}$ & References \\
\hline $\begin{array}{l}\text { Infectious } \\
\text { diseases (viral) }\end{array}$ & Viral proteins & $\begin{array}{l}\text { Limited by size of } \\
\text { viral genome, } \\
\text { make epitope } \\
\text { discovery simpler }\end{array}$ & CD4 and CD8 & Yes & 141 \\
\hline $\begin{array}{l}\text { Infectious } \\
\text { diseases (other } \\
\text { microbial) }\end{array}$ & $\begin{array}{l}\text { Bacterial } \\
\text { antigens }\end{array}$ & $\begin{array}{l}\text { Large bacterial or } \\
\text { parasite genomes } \\
\text { make epitope } \\
\text { discovery difficult }\end{array}$ & $\begin{array}{l}\text { Mostly CD4, } \\
\text { but also CD8 }\end{array}$ & $\begin{array}{l}\text { Requires } \\
\text { hypotheses } \\
\text { about targeted } \\
\text { antigens }\end{array}$ & 55 \\
\hline Cancer & $\begin{array}{l}\text { Tumor- } \\
\text { specific } \\
\text { antigens }\end{array}$ & $\begin{array}{l}\text { Mutations in } \\
\text { expressed genes, } \\
\text { other proteins } \\
\text { aberrantly } \\
\text { expressed in } \\
\text { tumor cells }\end{array}$ & CD4 and CD8 & $\begin{array}{l}\text { Yes, especially } \\
\text { for mutated } \\
\text { neo-antigens }\end{array}$ & $25,28-35$ \\
\hline Autoimmunity & Self-antigens & $\begin{array}{l}\text { In most cases, } \\
\text { antigens are not } \\
\text { known and range } \\
\text { of possibilities are } \\
\text { very large }\end{array}$ & CD4 and CD8 & $\begin{array}{l}\text { Requires } \\
\text { hypotheses } \\
\text { about targeted } \\
\text { antigens }\end{array}$ & 142 \\
\hline Allergy & Allergens & $\begin{array}{l}\text { Restricted to the } \\
\text { proteins present } \\
\text { in the allergen }\end{array}$ & CD4 & $\begin{array}{l}\text { Yes, especially if } \\
\text { immunogenic } \\
\text { proteins are } \\
\text { known }\end{array}$ & 61 \\
\hline
\end{tabular}


Table 2. Strategies for dissection of T cell responses.

\begin{tabular}{|c|c|c|c|c|c|}
\hline Approach & Goal & Description & Advantages & Disadvantages & References \\
\hline $\begin{array}{l}\text { Epitope } \\
\text { mapping using } \\
\text { ELlspot }\end{array}$ & $\begin{array}{l}\text { Mapping of T cell } \\
\text { epitopes and } \\
\text { quantifying } \\
\text { magnitudes of } \\
\text { functional T cell } \\
\text { responses. }\end{array}$ & $\begin{array}{l}\text { Synthetic pools of } \\
\text { peptides (typically } 15 \\
\text { residues) are used to } \\
\text { stimulate T cells using } \\
\text { autologous antigen } \\
\text { presenting cells. }\end{array}$ & $\begin{array}{l}\text { Simple and scalable } \\
\text { assay. }\end{array}$ & $\begin{array}{l}\text { Requires large numbers of } \\
\text { cells for screening and } \\
\text { mapping. Little information } \\
\text { gained about characteristics } \\
\text { of the } T \text { cells. Assumes that } T \\
\text { cells are functionally active. }\end{array}$ & 143,144 \\
\hline $\begin{array}{l}\text { Intracellular } \\
\text { cytokine } \\
\text { staining assays }\end{array}$ & $\begin{array}{l}\text { Functional profiling } \\
\text { of antigen-specific } \\
\text { cells. }\end{array}$ & $\begin{array}{l}\text { Identify antigen- } \\
\text { specific T cells by } \\
\text { measuring intracellular } \\
\text { cytokines induced by } \\
\text { antigen stimulation. }\end{array}$ & $\begin{array}{l}\text { Simultaneous } \\
\text { phenotypic and } \\
\text { functional } \\
\text { information } \\
\text { obtained. }\end{array}$ & $\begin{array}{l}\text { Relatively low sensitivity due } \\
\text { to background signal. T cells } \\
\text { must be functionally active. }\end{array}$ & 144,145 \\
\hline $\begin{array}{l}\text { Antigen } \\
\text { induced } \\
\text { induction of } \\
\text { CD154 (CD40L) } \\
\text { / CD137 } \\
\text { (41BB) }\end{array}$ & $\begin{array}{l}\text { Quantification and } \\
\text { profiling of } \\
\text { antigen-specific } \\
\text { cells }\end{array}$ & $\begin{array}{l}\text { Identify antigen- } \\
\text { specific T cells by } \\
\text { measuring induction of } \\
\text { cell surface markers } \\
\text { induced by antigen } \\
\text { stimulation. }\end{array}$ & $\begin{array}{l}\text { Can provide very } \\
\text { high sensitivity } \\
\text { when combined } \\
\text { with magnetic } \\
\text { enrichment. } \\
\text { Knowledge of HLA } \\
\text { restriction or exact } \\
\text { epitopes not } \\
\text { required. }\end{array}$ & $\begin{array}{l}\text { Requires relatively long term } \\
\text { stimulation and a source of } \\
\text { antigen presenting cells } \\
\text { (usually performed using } \\
\text { fresh PBMC samples) }\end{array}$ & 146,147 \\
\hline $\begin{array}{l}\text { Peptide-MHC } \\
\text { multimer } \\
\text { approaches }\end{array}$ & $\begin{array}{l}\text { Direct } \\
\text { identification and } \\
\text { profiling of antigen } \\
\text { specific } T \text { cells }\end{array}$ & $\begin{array}{l}\text { Recombinant } \\
\text { multimerized peptide- } \\
\text { MHC molecules are } \\
\text { used to directly stain T } \\
\text { cells through T cell } \\
\text { receptor binding. }\end{array}$ & $\begin{array}{l}\text { Directly identify } T \\
\text { cells by antigen } \\
\text { specificity and } \\
\text { allows for } \\
\text { simultaneous } \\
\text { phenotypic or } \\
\text { functional profiling. }\end{array}$ & $\begin{array}{l}\text { Cells with low affinity can be } \\
\text { hard to detect. Exact epitope } \\
\text { and HLA restriction needed. }\end{array}$ & $16,17,148$ \\
\hline $\begin{array}{l}\text { Sorting and } \\
\text { expansion } \\
\text { approaches }\end{array}$ & $\begin{array}{l}\text { Identify } \\
\text { frequencies, } \\
\text { antigen } \\
\text { recognition } \\
\text { capacity and T cell } \\
\text { receptors }\end{array}$ & $\begin{array}{l}\text { T cells are sorted based } \\
\text { on phenotypic marker } \\
\text { expression into many } \\
\text { different wells at } \\
\text { optimal numbers. After } \\
\text { expansion, T cells are } \\
\text { screened for antigen } \\
\text { specificity and } \\
\text { responding frequencies } \\
\text { back-calculated. }\end{array}$ & $\begin{array}{l}\text { Highly sensitive to } \\
\text { low frequencies and } \\
\text { allows for analysis } \\
\text { of T cell responses } \\
\text { targeting complex } \\
\text { antigens and } \\
\text { provides } \\
\text { simultaneous } \\
\text { phenotypic } \\
\text { information. Clonal } \\
\text { information can } \\
\text { also be obtained. }\end{array}$ & $\begin{array}{l}\text { Labor intensive and requires } \\
\text { large numbers of cells. } \\
\text { Limited resolution of } \\
\text { phenotypic profiles. }\end{array}$ & 149,150 \\
\hline $\begin{array}{l}\text { Next } \\
\text { generation } \\
\text { sequencing for } \\
\text { epitope } \\
\text { prediction }\end{array}$ & $\begin{array}{l}\text { Identification of } \\
\text { candidate antigens }\end{array}$ & $\begin{array}{l}\text { Deep sequencing of } \\
\text { cellular, viral or } \\
\text { microbial genomes for } \\
\text { identification (usually } \\
\text { in conjunction with } \\
\text { peptide-binding } \\
\text { prediction algorithms) } \\
\text { of candidate T cell } \\
\text { antigens. }\end{array}$ & $\begin{array}{l}\text { Sequencing costs } \\
\text { make large scale } \\
\text { analysis feasible. }\end{array}$ & $\begin{array}{l}\text { Candidate antigens need to } \\
\text { be validated by other means. } \\
\text { MHC binding prediction } \\
\text { algorithms are not perfect. } \\
\text { Antigen process and } \\
\text { presentation is difficult to } \\
\text { predict. }\end{array}$ & 24,31 \\
\hline $\begin{array}{l}\text { Peptide } \\
\text { elution and }\end{array}$ & $\begin{array}{l}\text { Identification of } \\
\text { candidate antigens }\end{array}$ & $\begin{array}{l}\text { Large numbers of } \\
\text { antigen presenting cells }\end{array}$ & $\begin{array}{l}\text { Unbiased method } \\
\text { for identifying }\end{array}$ & $\begin{array}{l}\text { Large amount of material } \\
\text { required and low abundance }\end{array}$ & 124,151 \\
\hline
\end{tabular}




\begin{tabular}{|l|l|l|l|l|}
\hline $\begin{array}{l}\text { mass } \\
\text { spectrometry }\end{array}$ & $\begin{array}{l}\text { (e.g., tumor cells or cell } \\
\text { lines) are used for } \\
\text { biochemical isolation of } \\
\text { MHC-bound peptides } \\
\text { to identify candidate T } \\
\text { cell antigens. }\end{array}$ & $\begin{array}{l}\text { peptides that have } \\
\text { been successfully } \\
\text { processed and } \\
\text { presented }\end{array}$ & $\begin{array}{l}\text { peptides are difficult to } \\
\text { detect. }\end{array}$ \\
\hline $\begin{array}{l}\text { Peptide-MHC } \\
\text { yeast display }\end{array}$ & $\begin{array}{l}\text { Unbiased } \\
\text { identification of } \\
\text { peptides } \\
\text { recognized by a } \\
\text { given T cell } \\
\text { receptor. }\end{array}$ & $\begin{array}{l}\text { After cloning of T cell } \\
\text { receptors for T cells of } \\
\text { interest, recombinant T } \\
\text { cell receptor proteins } \\
\text { are produced and used } \\
\text { to screen large libraries } \\
\text { of yeast displaying } \\
\text { peptide-MHCs. }\end{array}$ & $\begin{array}{l}\text { Possible to identify } \\
\text { antigens without } \\
\text { knowing the origin } \\
\text { of the antigen. }\end{array}$ & $\begin{array}{l}\text { Low throughput in terms of } \\
\text { the number of T cells that can } \\
\text { be analyzed and requires a } \\
\text { new yeast library for each } \\
\text { MHC allele. }\end{array}$ \\
\hline
\end{tabular}

Box 1. Challenges in studying CD4+ T cells with peptide-MHC multimers.

Just as CD8+ T cells can be identified using MHC class I multimers, $C D 4+T$ cells can be labeled using multimers of $\mathrm{MHC}$ class II. However, several factors make these studies significantly more challenging.

MHC class II protein expression. Whereas most MHC class I proteins can be expressed as recombinant proteins in bacteria and refolded in the presence of peptide (or conditional peptide) ${ }^{79}$ ligands, refolding of MHC class II proteins is notoriously inefficient. Instead MHC class II are typically expressed using insect ${ }^{152}$ or mammalian ${ }^{82}$ expression systems which are generally more challenging to setup and optimize.

Variable peptide binding characteristics. Compared to $\mathrm{MHC}$ class I, MHC class II proteins have more diverse properties when it comes to binding to peptide ligands. In addition to their wider range of binding motifs, some MHC class II alleles can often bind the same peptides in multiple registers (e.g., different parts of the peptide being anchored to the $\mathrm{MHC})^{83,153}$. The consequence is that some alleles require the careful design of tethered peptide ligands and are therefore not amenable to high throughput production approaches. This seems to be the case especially for human HLA-DP and DQ (mouse I-A) proteins. Some are amenable to peptide exchange (e.g., cleavage and release of tethered CLIP peptide) and do allow for higher throughput production (e.g., various human HLA-DR alleles and mouse I-E).

Less predictable peptide binding motifs. Related to the previous point, motifs for peptides binding to MHC class II are more complicated and therefore it is more difficult to predict if any given peptide will bind to an MHC class II allele of interest ${ }^{154}$.

Higher diversity of alleles expressed by human populations. Several MHC class I alleles have conveniently high allele frequencies in well-studied human populations. For instance, the HLA-A*0201 and -A*1101 alleles are expressed by approximately half of Caucasian and Chinese ethnicity populations, respectively. In contrast, the frequencies of the most common HLA-DR alleles vary more dramatically between various human populations and the expression of any given allele in any given population rarely exceeds $30 \%$.

Low frequency antigen-specific effector and memory CD4+ T cells. Studies in infectious diseases and in allergy where peptide-MHC tetramers have been used to identify antigen specific CD4 T cells have highlighted that these cells are often found at remarkably low frequencies. This is likely because CD4+ T cells appear to target a broader range of peptide antigens (response spread across more different epitopes) and because CD4+ T cell responses typically have lower magnitudes in terms of frequencies observed the peak of the response and in terms of the frequencies observed after contraction and memory formation ${ }^{155,156}$. 
Lower affinity $\mathrm{T}$ cells more common. Although $\mathrm{MHC}$ class I restricted CD8+ T cells with low affinities for antigen have also been reported, low affinity CD4+ T cells are more commonly reported. This may be influenced primarily by the lack of CD4 mediated stabilization of the MHC II-TCR complex ${ }^{77,78}$. Low T cell receptor affinity for peptide-MHC makes multimer staining much less efficient, and in some cases impossible ${ }^{157,158}$.

\section{References:}

1. Robbins, P. F. et al. Tumor regression in patients with metastatic synovial cell sarcoma and melanoma using genetically engineered lymphocytes reactive with NY-ESO-1. J. Clin. Oncol. 29, 917-24 (2011).

2. Morgan, R. A. et al. Cancer regression and neurological toxicity following anti-MAGE-A3 TCR gene therapy. J. Immunother. 36, 133-51 (2013).

3. Neuenhahn, M. et al. Transfer of minimally manipulated CMV-specific T cells from stem cell or thirdparty donors to treat CMV infection after allo-HSCT. Leukemia (2017). doi:10.1038/leu.2017.16

4. Cobbold, M. et al. Adoptive transfer of cytomegalovirus-specific CTL to stem cell transplant patients after selection by HLA-peptide tetramers. J. Exp. Med. 202, 379-86 (2005).

5. Wambre, E. et al. Specific immunotherapy modifies allergen-specific CD4(+) T-cell responses in an epitope-dependent manner. J. Allergy Clin. Immunol. 133, 872-9.e7 (2014).

6. Odegard, J. M., Nepom, G. T. \& Wambre, E. Biomarkers for antigen immunotherapy in allergy and type 1 diabetes. Clin. Immunol. 161, 44-50 (2015).

7. Radvanyi, L. G. et al. Specific lymphocyte subsets predict response to adoptive cell therapy using expanded autologous tumor-infiltrating lymphocytes in metastatic melanoma patients. Clin. Cancer Res. 18, 6758-70 (2012).

8. Darrah, P. A. et al. Multifunctional TH1 cells define a correlate of vaccine-mediated protection against Leishmania major. Nat. Med. 13, 843-50 (2007).

9. Davis, M. M., Altman, J. D. \& Newell, E. W. Interrogating the repertoire: broadening the scope of peptide-MHC multimer analysis. Nat. Rev. Immunol. 11, 551-8 (2011).

10. Chien, Y. H. \& Davis, M. M. How alpha beta T-cell receptors 'see' peptide/MHC complexes. Immunol. Today 14, 597-602 (1993).

11. Germain, R. N. MHC-dependent antigen processing and peptide presentation: providing ligands for T lymphocyte activation. Cell 76, 287-99 (1994).

12. Pape, K. A. et al. Use of adoptive transfer of T-cell-antigen-receptor-transgenic T cell for the study of Tcell activation in vivo. Immunol. Rev. 156, 67-78 (1997).

13. Hogquist, K. A. et al. T cell receptor antagonist peptides induce positive selection. Cell 76, 17-27 (1994).

14. Robey, E. A. et al. The level of CD8 expression can determine the outcome of thymic selection. Cell 69, 1089-96 (1992).

15. Akram, A. \& Inman, R. D. Immunodominance: a pivotal principle in host response to viral infections. Clin. Immunol. 143, 99-115 (2012).

16. Altman, J. D. et al. Phenotypic analysis of antigen-specific T lymphocytes. Science 274, 94-6 (1996).

17. Bentzen, A. K. \& Hadrup, S. R. Evolution of MHC-based technologies used for detection of antigenresponsive T cells. Cancer Immunol. Immunother. (2017). doi:10.1007/s00262-017-1971-5

18. Lee, P. P. et al. Characterization of circulating T cells specific for tumor-associated antigens in melanoma patients. Nat. Med. 5, 677-85 (1999). 
19. Coulie, P. G., Van den Eynde, B. J., van der Bruggen, P. \& Boon, T. Tumour antigens recognized by T lymphocytes: at the core of cancer immunotherapy. Nat. Rev. Cancer 14, 135-46 (2014).

20. Coulie, P. G. et al. A new gene coding for a differentiation antigen recognized by autologous cytolytic $T$ lymphocytes on HLA-A2 melanomas. J. Exp. Med. 180, 35-42 (1994).

21. Van Nuffel, A. M. T. et al. Intravenous and intradermal TriMix-dendritic cell therapy results in a broad Tcell response and durable tumor response in a chemorefractory stage IV-M1c melanoma patient. Cancer Immunol. Immunother. 61, 1033-43 (2012).

22. Andersen, R. S. et al. Dissection of T-cell antigen specificity in human melanoma. Cancer Res. 72, (2012).

23. Kvistborg, P. et al. TIL therapy broadens the tumor-reactive CD8(+) T cell compartment in melanoma patients. Oncoimmunology 1, 409-418 (2012).

24. Rizvi, N. A. et al. Mutational landscape determines sensitivity to PD-1 blockade in non-small cell lung cancer. Science (80-. ). 348, (2015).

25. Snyder, A. et al. Genetic basis for clinical response to CTLA-4 blockade in melanoma. N. Engl. J. Med. 371, 2189-99 (2014).

26. Rooney, M. S., Shukla, S. A., Wu, C. J., Getz, G. \& Hacohen, N. Article Molecular and Genetic Properties of Tumors Associated with Local Immune Cytolytic Activity. Cell 160, 48-61 (2014).

27. Van Allen, E. M. et al. Genomic correlates of response to CTLA-4 blockade in metastatic melanoma. Science 350, 207-11 (2015).

28. Strønen, E. et al. Targeting of cancer neoantigens with donor-derived T cell receptor repertoires. Science (80-. ). 2288, 1-11 (2016).

29. Gros, A. et al. Prospective identification of neoantigen-specific lymphocytes in the peripheral blood of melanoma patients. Nat. Med. (2016). doi:10.1038/nm.4051

30. McGranahan, N. et al. Clonal neoantigens elicit T cell immunoreactivity and sensitivity to immune checkpoint blockade. Science 351, 1463-9 (2016).

31. van Rooij, N. et al. Tumor exome analysis reveals neoantigen-specific T-cell reactivity in an ipilimumabresponsive melanoma. J. Clin. Oncol. 31, e439-42 (2013).

32. Bassani-Sternberg, M. et al. Direct identification of clinically relevant neoepitopes presented on native human melanoma tissue by mass spectrometry. Nat. Commun. 7, 13404 (2016).

33. Bentzen, A. K. et al. Large-scale detection of antigen-specific T cells using peptide-MHC-I multimers labeled with DNA barcodes. Nat. Biotechnol. 34, 1037-1045 (2016).

34. Wick, D. A. et al. Surveillance of the tumor mutanome by T cells during progression from primary to recurrent ovarian cancer. Clin. Cancer Res. 20, 1125-34 (2014).

35. Rajasagi, M. et al. Systematic identification of personal tumor-specific neoantigens in chronic lymphocytic leukemia. Blood 124, 453-62 (2014).

36. Verdegaal, E. M. E. et al. Neoantigen landscape dynamics during human melanoma-T cell interactions. Nature 536, (2016).

37. Schumacher, T. N. \& Schreiber, R. D. Neoantigens in cancer immunotherapy. 348, (2015).

38. Rizvi, N. A. et al. Cancer immunology. Mutational landscape determines sensitivity to PD-1 blockade in non-small cell lung cancer. Science 348, 124-8 (2015).

39. Gubin, M. M. et al. Checkpoint blockade cancer immunotherapy targets tumour-specific mutant antigens. Nature 515, 577-81 (2014).

40. Rizvi, N. A. et al. Cancer immunology. Mutational landscape determines sensitivity to PD-1 blockade in non-small cell lung cancer. Science 348, 124-8 (2015).

41. Hugo, W. et al. Genomic and Transcriptomic Features of Response to Anti-PD-1 Therapy in Metastatic Melanoma. Cell 165, 35-44 (2016).

42. Ott, P. A. et al. An immunogenic personal neoantigen vaccine for patients with melanoma. Nature 
(2017). doi:10.1038/nature22991

43. Gerlinger, M. et al. Intratumor heterogeneity and branched evolution revealed by multiregion sequencing. N. Engl. J. Med. 366, 883-92 (2012).

44. Palmer, D. C. et al. Cish actively silences TCR signaling in CD8+ T cells to maintain tumor tolerance. J. Exp. Med. 212, 2095-113 (2015).

45. Chidrawar, S. et al. Cytomegalovirus-seropositivity has a profound influence on the magnitude of major lymphoid subsets within healthy individuals. Clin. Exp. Immunol. 155, 423-32 (2009).

46. Gordon, C. L. et al. Tissue reservoirs of antiviral T cell immunity in persistent human CMV infection. J. Exp. Med. 214, 651-667 (2017).

47. Colugnati, F. A. B., Staras, S. A. S., Dollard, S. C. \& Cannon, M. J. Incidence of cytomegalovirus infection among the general population and pregnant women in the United States. BMC Infect. Dis. 7, 71 (2007).

48. Hadrup, S. R. et al. Longitudinal studies of clonally expanded CD8 T cells reveal a repertoire shrinkage predicting mortality and an increased number of dysfunctional cytomegalovirus-specific $T$ cells in the very elderly. J. Immunol. 176, (2006).

49. Furman, D. et al. Cytomegalovirus infection enhances the immune response to influenza. Sci. Transl. Med. 7, 281ra43-281ra43 (2015).

50. Kamphorst, A. O. et al. Rescue of exhausted CD8 T cells by PD-1-targeted therapies is CD28-dependent. Science 355, 1423-1427 (2017).

51. Williams, M. A. et al. Cutting edge: persistent viral infection prevents tolerance induction and escapes immune control following CD28/CD40 blockade-based regimen. J. Immunol. 169, 5387-91 (2002).

52. Lanzavecchia, A. \& Sallusto, F. Understanding the generation and function of memory T cell subsets. Curr. Opin. Immunol. 17, 326-32 (2005).

53. Sylwester, A. W. et al. Broadly targeted human cytomegalovirus-specific CD4+ and CD8+ T cells dominate the memory compartments of exposed subjects. J. Exp. Med. 202, 673-85 (2005).

54. Lindestam Arlehamn, C. S. et al. A Quantitative Analysis of Complexity of Human Pathogen-Specific CD4 T Cell Responses in Healthy M. tuberculosis Infected South Africans. PLoS Pathog. 12, e1005760 (2016).

55. Lindestam Arlehamn, C. S., Lewinsohn, D., Sette, A. \& Lewinsohn, D. Antigens for CD4 and CD8 T cells in tuberculosis. Cold Spring Harb. Perspect. Med. 4, a018465 (2014).

56. Höhn, H. et al. MHC class II tetramer guided detection of Mycobacterium tuberculosis-specific CD4+ T cells in peripheral blood from patients with pulmonary tuberculosis. Scand. J. Immunol. 65, 467-78 (2007).

57. Newell, E. W. et al. Combinatorial tetramer staining and mass cytometry analysis facilitate T-cell epitope mapping and characterization. Nat. Biotechnol. (2013). doi:10.1038/nbt.2593

58. Yang, J. et al. Expression of HLA-DP0401 molecules for identification of DP0401 restricted antigen specific T cells. J. Clin. Immunol. 25, 428-36 (2005).

59. Archila, L. L. D. \& Kwok, W. W. Tetramer-Guided Epitope Mapping: A Rapid Approach to Identify HLARestricted T-Cell Epitopes from Composite Allergens. Methods Mol. Biol. 1592, 199-209 (2017).

60. Hinz, D. et al. Lack of allergy to timothy grass pollen is not a passive phenomenon but associated with the allergen-specific modulation of immune reactivity. Clin. Exp. Allergy 46, 705-19 (2016).

61. Wambre, E., James, E. A. \& Kwok, W. W. Characterization of CD4+ T cell subsets in allergy. Curr. Opin. Immunol. 24, 700-6 (2012).

62. Kracht, M. J. L. et al. Autoimmunity against a defective ribosomal insulin gene product in type 1 diabetes. Nat. Med. 23, 501-507 (2017).

63. Roep, B. O., Kracht, M. J., van Lummel, M. \& Zaldumbide, A. A roadmap of the generation of neoantigens as targets of the immune system in type 1 diabetes. Curr. Opin. Immunol. 43, 67-73 (2016).

64. Salou, M., Nicol, B., Garcia, A. \& Laplaud, D.-A. Involvement of CD8(+) T Cells in Multiple Sclerosis. Front. 
Immunol. 6, 604 (2015).

65. McGinty, J. W. et al. Recognition of posttranslationally modified GAD65 epitopes in subjects with type 1 diabetes. Diabetes 63, 3033-3040 (2014).

66. Rondas, D. et al. Citrullinated glucose-regulated protein 78 is an autoantigen in type 1 diabetes. Diabetes 64, 573-586 (2015).

67. Roep, B. O., Kracht, M. J., van Lummel, M. \& Zaldumbide, A. A roadmap of the generation of neoantigens as targets of the immune system in type 1 diabetes. Curr. Opin. Immunol. 43, 67-73 (2016).

68. McLaughlin, R. J., Spindler, M. P., van Lummel, M. \& Roep, B. O. Where, How, and When: Positioning Posttranslational Modification Within Type 1 Diabetes Pathogenesis. Curr. Diab. Rep. 16, (2016).

69. Suárez-Fueyo, A., Bradley, S. J. \& Tsokos, G. C. T cells in Systemic Lupus Erythematosus. Curr. Opin. Immunol. 43, 32-38 (2016).

70. Carvalheiro, H., da Silva, J. A. P. \& Souto-Carneiro, M. M. Potential roles for CD8+ T cells in rheumatoid arthritis. Autoimmun. Rev. 12, 401-409 (2013).

71. Andersen, R. S. et al. High frequency of T cells specific for cryptic epitopes in melanoma patients. Oncoimmunology 2, e25374 (2013).

72. Spath, S. et al. Dysregulation of the Cytokine GM-CSF Induces Spontaneous Phagocyte Invasion and Immunopathology in the Central Nervous System. Immunity 46, 245-260 (2017).

73. Schumacher, T. N. M. et al. Peptide selection by MHC class I molecules. Nature 350, 703-706 (1991).

74. Nielsen, M., Justesen, S., Lund, O., Lundegaard, C. \& Buus, S. NetMHCIlpan-2.0 - Improved pan-specific HLA-DR predictions using a novel concurrent alignment and weight optimization training procedure. Immunome Res. 6, 9 (2010).

75. Andreatta, M. et al. Accurate pan-specific prediction of peptide-MHC class II binding affinity with improved binding core identification. Immunogenetics 67, 641-50 (2015).

76. Braendstrup, P. et al. MHC class II tetramers made from isolated recombinant $\alpha$ and $\beta$ chains refolded with affinity-tagged peptides. PLoS One 8, e73648 (2013).

77. Crawford, F., Kozono, H., White, J., Marrack, P. \& Kappler, J. Detection of antigen-specific T cells with multivalent soluble class II MHC covalent peptide complexes. Immunity 8, 675-82 (1998).

78. Rahim, A. et al. Potent T Cell Activation with Dimeric Peptide-Major Histocompatibility Complex Class II Ligand: The Role of CD4 Coreceptor. J. Exp. Med 188, 1633-1640 (1998).

79. Toebes, M. et al. Design and use of conditional MHC class I ligands. Nat. Med. 12, 246-51 (2006).

80. Saini, S. K. et al. Dipeptides catalyze rapid peptide exchange on MHC class I molecules. Proc. Natl. Acad. Sci. U. S. A. 112, 202-7 (2015).

81. Leisner, C. et al. One-pot, mix-and-read peptide-MHC tetramers. PLoS One 3, e1678 (2008).

82. Day, C. L. et al. Ex vivo analysis of human memory CD4 T cells specific for hepatitis C virus using MHC class II tetramers. J. Clin. Invest. 112, 831-42 (2003).

83. Landais, E. et al. New design of MHC class II tetramers to accommodate fundamental principles of antigen presentation. J. Immunol. 183, 7949-57 (2009).

84. Lu, Y.-C. et al. Efficient identification of mutated cancer antigens recognized by $T$ cells associated with durable tumor regressions. Clin. Cancer Res. 20, 3401-10 (2014).

85. Birnbaum, M. E., Dong, S. \& Garcia, K. C. Diversity-oriented approaches for interrogating T-cell receptor repertoire, ligand recognition, and function. Immunol. Rev. 250, 82-101 (2012).

86. Birnbaum, M. E. et al. Deconstructing the peptide-MHC specificity of T cell recognition. Cell 157, 107387 (2014).

87. Yadav, M. et al. Predicting immunogenic tumour mutations by combining mass spectrometry and exome sequencing. Nature 515, 572-6 (2014).

88. Newell, E. W. Higher throughput methods of identifying T cell epitopes for studying outcomes of altered 
antigen processing and presentation. Front. Immunol. 4, 430 (2013).

89. Vigneron, N. et al. An antigenic peptide produced by peptide splicing in the proteasome. Science 304, 587-90 (2004).

90. Liepe, J. et al. A large fraction of HLA class I ligands are proteasome-generated spliced peptides. Science 354, 354-358 (2016).

91. Hadrup, S. R. et al. Parallel detection of antigen-specific T-cell responses by multidimensional encoding of MHC multimers. Nat. Methods 6, (2009).

92. Newell, E. W., Klein, L. O., Yu, W. \& Davis, M. M. Simultaneous detection of many T-cell specificities using combinatorial tetramer staining. Nat. Methods 6, 497-9 (2009).

93. Kvistborg, P. et al. Thinking Outside the Gate: Single-Cell Assessments in Multiple Dimensions. Immunity 42, 591-592 (2015).

94. Appay, V., Van Lier, R. A. W., Sallusto, F. \& Roederer, M. Phenotype and function of human T lymphocyte subsets: Consensus and issues. Cytometry Part A 73, 975-983 (2008).

95. Ornatsky, O. I., Baranov, V. I., Bandura, D. R., Tanner, S. D. \& Dick, J. Messenger RNA Detection in Leukemia Cell lines by Novel Metal-Tagged in situ Hybridization using Inductively Coupled Plasma Mass Spectrometry. Transl. Oncogenomics 1, 1-9 (2006).

96. Bandura, D. R. et al. Mass cytometry: technique for real time single cell multitarget immunoassay based on inductively coupled plasma time-of-flight mass spectrometry. Anal. Chem. 81, 6813-22 (2009).

97. Bendall, S. C. et al. Single-Cell Mass Cytometry of Differential Immune and Drug Responses Across a Human Hematopoietic Continuum. Science (80-. ). 332, 687-696 (2011).

98. Cheng, Y. \& Newell, E. W. Deep Profiling Human T Cell Heterogeneity by Mass Cytometry. Adv. Immunol. 131, 101-34 (2016).

99. Mair, F. et al. The end of gating? An introduction to automated analysis of high dimensional cytometry data. Eur. J. Immunol. 46, 34-43 (2016).

100. Newell, E. W. \& Cheng, Y. Mass cytometry: blessed with the curse of dimensionality. Nat. Immunol. 17, 890-5 (2016).

101. Spitzer, M. H. \& Nolan, G. P. Mass Cytometry: Single Cells, Many Features. Cell 165, 780-91 (2016).

102. Wong, M. T. et al. A High-Dimensional Atlas of Human T Cell Diversity Reveals Tissue-Specific Trafficking and Cytokine Signatures. Immunity 45, 442-456 (2015).

103. Newell, E. W., Sigal, N., Bendall, S. C., Nolan, G. P. \& Davis, M. M. Cytometry by Time-of-Flight Shows Combinatorial Cytokine Expression and Virus-Specific Cell Niches within a Continuum of CD8 + T Cell Phenotypes. Immunity 36, 142-152 (2012).

104. Cheng, Y., Wong, M. T., van der Maaten, L. \& Newell, E. W. Categorical Analysis of Human T Cell Heterogeneity with One-Dimensional Soli-Expression by Nonlinear Stochastic Embedding. J. Immunol. 196, 924-32 (2016).

105. Wistuba-Hamprecht, K. et al. Establishing High Dimensional Immune Signatures from Peripheral Blood via Mass Cytometry in a Discovery Cohort of Stage IV Melanoma Patients. J. Immunol. 1600875 (2016). doi:10.4049/jimmunol.1600875

106. Krams, S. M., Schaffert, S., Lau, A. H. \& Martinez, O. M. Applying Mass Cytometry to the Analysis of Lymphoid Populations in Transplantation. Am. J. Transplant (2016). doi:10.1111/ajt.14145

107. Brooks, M. Insulinoma and abdominal tuberculosis. Scott. Med. J. 33, 207-8 (1988).

108. Xu, Q., Schlabach, M. R., Hannon, G. J. \& Elledge, S. J. Design of 240,000 orthogonal 25 mer DNA barcode probes. Proc. Natl. Acad. Sci. U. S. A. 106, 2289-94 (2009).

109. MacBeath, G. \& Schreiber, S. L. Printing proteins as microarrays for high-throughput function determination. Science 289, 1760-3 (2000).

110. Soen, Y., Chen, D. S., Kraft, D. L., Davis, M. M. \& Brown, P. O. Detection and characterization of cellular 
immune responses using peptide-MHC microarrays. PLoS Biol. 1, E65 (2003).

111. Stone, J. D., Demkowicz, W. E. \& Stern, L. J. HLA-restricted epitope identification and detection of functional T cell responses by using MHC-peptide and costimulatory microarrays. Proc. Natl. Acad. Sci. U. S. A. 102, 3744-9 (2005).

112. Chen, D. S. et al. Marked differences in human melanoma antigen-specific T cell responsiveness after vaccination using a functional microarray. PLoS Med. 2, e265 (2005).

113. Deviren, G., Gupta, K., Paulaitis, M. E. \& Schneck, J. P. Detection of antigen-specific T cells on p/MHC microarrays. J. Mol. Recognit. 20, 32-8

114. Kwong, G. A. et al. Modular nucleic acid assembled p/MHC microarrays for multiplexed sorting of antigen-specific T cells. J. Am. Chem. Soc. 131, 9695-703 (2009).

115. Brooks, S. E. et al. Application of the pMHC Array to Characterise Tumour Antigen Specific T Cell Populations in Leukaemia Patients at Disease Diagnosis. PLoS One 10, e0140483 (2015).

116. Klinger, M. et al. Multiplex Identification of Antigen-Specific T Cell Receptors Using a Combination of Immune Assays and Immune Receptor Sequencing. PLoS One 10, e0141561 (2015).

117. Novak, E. J. et al. Tetramer-guided epitope mapping: rapid identification and characterization of immunodominant CD4+ T cell epitopes from complex antigens. J. Immunol. 166, 6665-70 (2001).

118. Robins, H. S. et al. Comprehensive assessment of T-cell receptor beta-chain diversity in alphabeta T cells. Blood 114, 4099-107 (2009).

119. Davis, M. M. \& Bjorkman, P. J. T-cell antigen receptor genes and T-cell recognition. Nature 334, 395-402 (1988).

120. van Buuren, M. M. et al. HLA micropolymorphisms strongly affect peptide-MHC multimer-based monitoring of antigen-specific CD8+ T cell responses. J. Immunol. (2014). doi:10.4049/jimmunol.1301770

121. Frøsig, T. M. et al. Design and validation of conditional ligands for HLA-B*08:01, HLA-B*15:01, HLAB*35:01, and HLA-B*44:05. Cytom. Part A 87, 967-975 (2015).

122. Mason, D. A very high level of crossreactivity is an essential feature of the T-cell receptor. Immunol. Today 19, 395-404 (1998).

123. Lundegaard, C., Lund, O., Buus, S. \& Nielsen, M. Major histocompatibility complex class I binding predictions as a tool in epitope discovery. Immunology 130, 309-18 (2010).

124. Abelin, J. G. et al. Mass Spectrometry Profiling of HLA-Associated Peptidomes in Mono-allelic Cells Enables More Accurate Epitope Prediction. Immunity 46, 315-326 (2017).

125. Malaker, S. A. et al. Identification and Characterization of Complex Glycosylated Peptides Presented by the MHC Class II Processing Pathway in Melanoma. J. Proteome Res. 16, 228-237 (2017).

126. Fritsch, E. F. et al. HLA-binding properties of tumor neoepitopes in humans. Cancer Immunol. Res. 2, 522-9 (2014).

127. The problem with neoantigen prediction. Nat. Biotechnol. 35, 97 (2017).

128. Liu, X. S. \& Mardis, E. R. Applications of Immunogenomics to Cancer. Cell 168, 600-612 (2017).

129. Osborne, G. W., Andersen, S. B. \& Battye, F. L. Development of a novel cell sorting method that samples population diversity in flow cytometry. Cytometry. A 87, 1047-51 (2015).

130. Klein, A. M. et al. Droplet Barcoding for Single-Cell Transcriptomics Applied to Embryonic Stem Cells. Cell 161, 1187-1201 (2015).

131. Macosko, E. Z. et al. Highly parallel genome-wide expression profiling of individual cells using nanoliter droplets. Cell 161, 1202-1214 (2015).

132. Marlon Stoeckius, Christoph Hafemeister, William Stephenson, Brian Houck-Loomis, Harold Swerdlow, Rahul Satija, P. S. Large scale simultaneous measurement of epitopes and transcriptomes in single cells. bioRxiv March 2, (2017). 
133. van Buggenum, J. A. G. L. et al. A covalent and cleavable antibody-DNA conjugation strategy for sensitive protein detection via immuno-PCR. Sci. Rep. 6, 22675 (2016).

134. Moon, J. J. et al. Naive CD4(+) T cell frequency varies for different epitopes and predicts repertoire diversity and response magnitude. Immunity 27, 203-13 (2007).

135. Yu, W. et al. Clonal Deletion Prunes but Does Not Eliminate Self-Specific $\alpha \beta C D 8(+)$ T Lymphocytes. Immunity 42, 929-41 (2015).

136. Zoete, V., Irving, M., Ferber, M., Cuendet, M. A. \& Michielin, O. Structure-Based, Rational Design of T Cell Receptors. Front. Immunol. 4, 268 (2013).

137. Dash, P. et al. Quantifiable predictive features define epitope-specific T cell receptor repertoires. Nature (2017). doi:10.1038/nature22383

138. Glanville, J. et al. Identifying specificity groups in the T cell receptor repertoire. Nature (2017). doi:10.1038/nature22976

139. Sela-culang, I. et al. Resource Using a Combined Computational-Experimental Approach to Predict Antibody-Specific B Cell Epitopes. Struct. Des. 22, 646-657 (2014).

140. Furman, D. et al. Expression of specific inflammasome gene modules stratifies older individuals into two extreme clinical and immunological states. Nat. Med. 23, 174-184 (2017).

141. Sette, A. \& Peters, B. Immune epitope mapping in the post-genomic era: lessons for vaccine development. Curr. Opin. Immunol. 19, 106-10 (2007).

142. Anderson, R. P. \& Jabri, B. Vaccine against autoimmune disease: antigen-specific immunotherapy. Curr. Opin. Immunol. 25, 410-7 (2013).

143. Czerkinsky, C. C., Nilsson, L. A., Nygren, H., Ouchterlony, O. \& Tarkowski, A. A solid-phase enzyme-linked immunospot (ELISPOT) assay for enumeration of specific antibody-secreting cells. J. Immunol. Methods 65, 109-21 (1983).

144. Draenert, R. et al. Comparison of overlapping peptide sets for detection of antiviral CD8 and CD4 T cell responses. J. Immunol. Methods 275, 19-29 (2003).

145. Waldrop, S. L., Pitcher, C. J., Peterson, D. M., Maino, V. C. \& Picker, L. J. Determination of antigenspecific memory/effector CD4+ T cell frequencies by flow cytometry: evidence for a novel, antigenspecific homeostatic mechanism in HIV-associated immunodeficiency. J. Clin. Invest. 99, 1739-50 (1997).

146. Bacher, P. et al. Antigen-reactive T cell enrichment for direct, high-resolution analysis of the human naive and memory Th cell repertoire. J. Immunol. 190, 3967-76 (2013).

147. Bacher, P. et al. Regulatory T Cell Specificity Directs Tolerance versus Allergy against Aeroantigens in Humans. Cell 167, 1067-1078.e16 (2016).

148. Appay, V. \& Rowland-Jones, S. L. The assessment of antigen-specific CD8+ T cells through the combination of MHC class I tetramer and intracellular staining. J. Immunol. Methods 268, 9-19 (2002).

149. Geiger, R., Duhen, T., Lanzavecchia, A. \& Sallusto, F. Human naive and memory CD4+ T cell repertoires specific for naturally processed antigens analyzed using libraries of amplified T cells. J. Exp. Med. 206, 1525-34 (2009).

150. Becattini, S. et al. T cell immunity. Functional heterogeneity of human memory $\mathrm{CD}^{+}{ }^{+} \mathrm{T}$ cell clones primed by pathogens or vaccines. Science 347, 400-6 (2015).

151. Cox, A. L. et al. Identification of a peptide recognized by five melanoma-specific human cytotoxic $T$ cell lines. Science 264, 716-9 (1994).

152. Kozono, H., White, J., Clements, J., Marrack, P. \& Kappler, J. Production of soluble MHC class II proteins with covalently bound single peptides. Nature 369, 151-154 (1994).

153. Bankovich, A. J., Girvin, A. T., Moesta, A. K. \& Garcia, K. C. Peptide register shifting within the MHC groove: theory becomes reality. Mol. Immunol. 40, 1033-9 (2004). 
154. Lin, H. H., Zhang, G. L., Tongchusak, S., Reinherz, E. L. \& Brusic, V. Evaluation of MHC-Il peptide binding prediction servers: applications for vaccine research. BMC Bioinformatics 9 Suppl 12, S22 (2008).

155. Su, L. F., Kidd, B. A., Han, A., Kotzin, J. J. \& Davis, M. M. Virus-specific CD4(+) memory-phenotype T cells are abundant in unexposed adults. Immunity 38, 373-83 (2013).

156. Uchtenhagen, H. et al. Efficient ex vivo analysis of CD4+ T-cell responses using combinatorial HLA class II tetramer staining. Nat. Commun. 7, 12614 (2016).

157. Lissina, A. et al. Protein kinase inhibitors substantially improve the physical detection of T-cells with peptide-MHC tetramers. J. Immunol. Methods 340, 11-24 (2009).

158. Xie, J. et al. Photocrosslinkable pMHC monomers stain T cells specifically and cause ligand-bound TCRs to be 'preferentially' transported to the cSMAC. Nat. Immunol. 13, 674-80 (2012). 
Figure 1: Antigen processing and T cell recognions strategies. A) a schematic overview of the different pathogens and protein modifications leading to potential epitope presentation and $T$ cell recognition in different diseases. B) a schematic overview of the three multiplex MHC multimer technologies discussed in depth throughout this perspective, fluorescently labeled combinatorial encoded MHC multimers, heavy-metal labeled combinatorial encoded MHC multimers and DNA barcode labeled MHC multimers

A

B
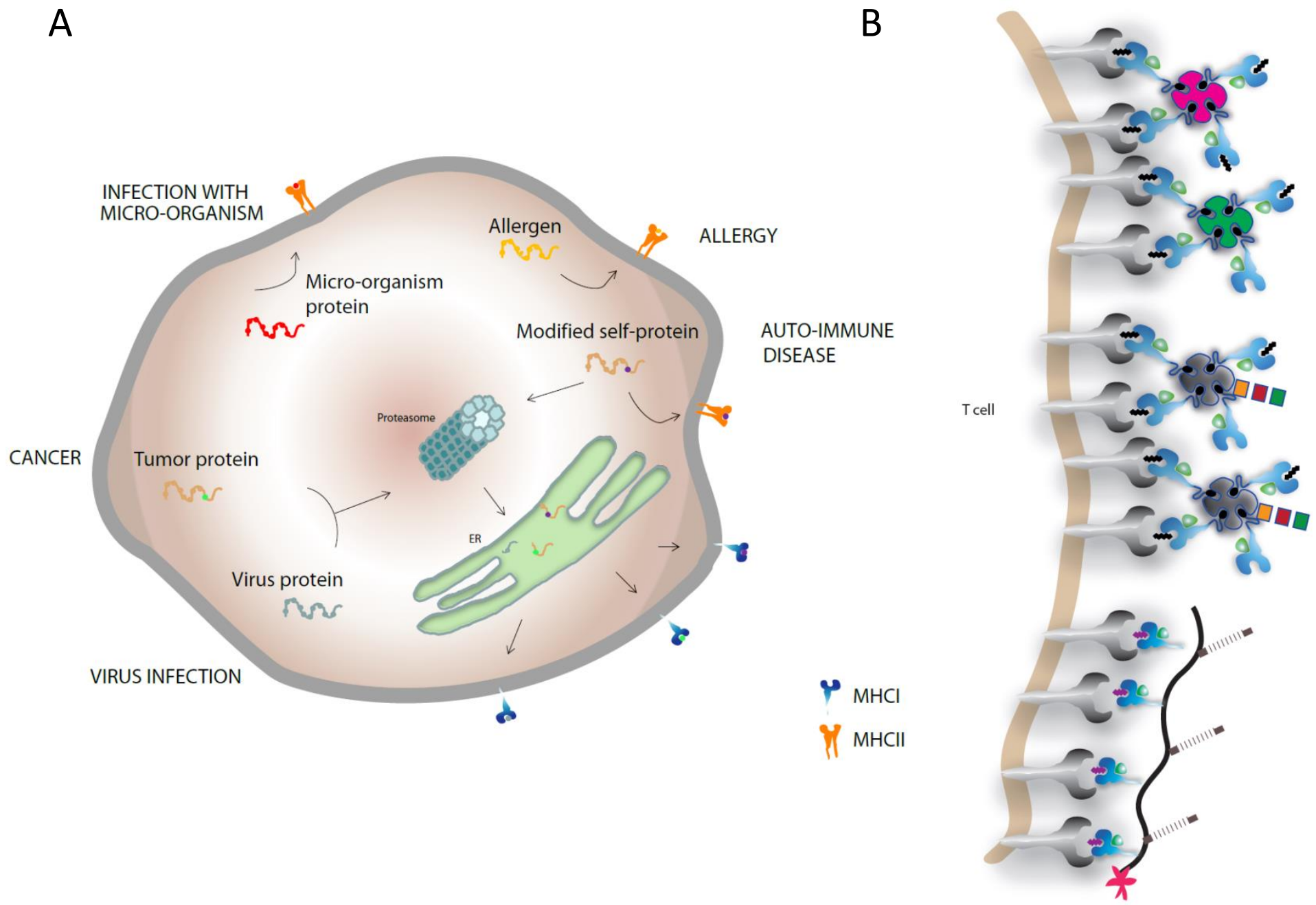

1. Fluorescently-labeled combinatorial encoded MHC multimers 
Figure 2: Epitope mapping - gaining insight to disease mechanisms. A generic workflow for T cell epitope mapping strategies using either the direct or indirect epitope mapping approach. The workflow address different technology options for dissecting the $\mathrm{T}$ cell recognition profile in disease relevant settings.

\section{'Direct' immunology approach}

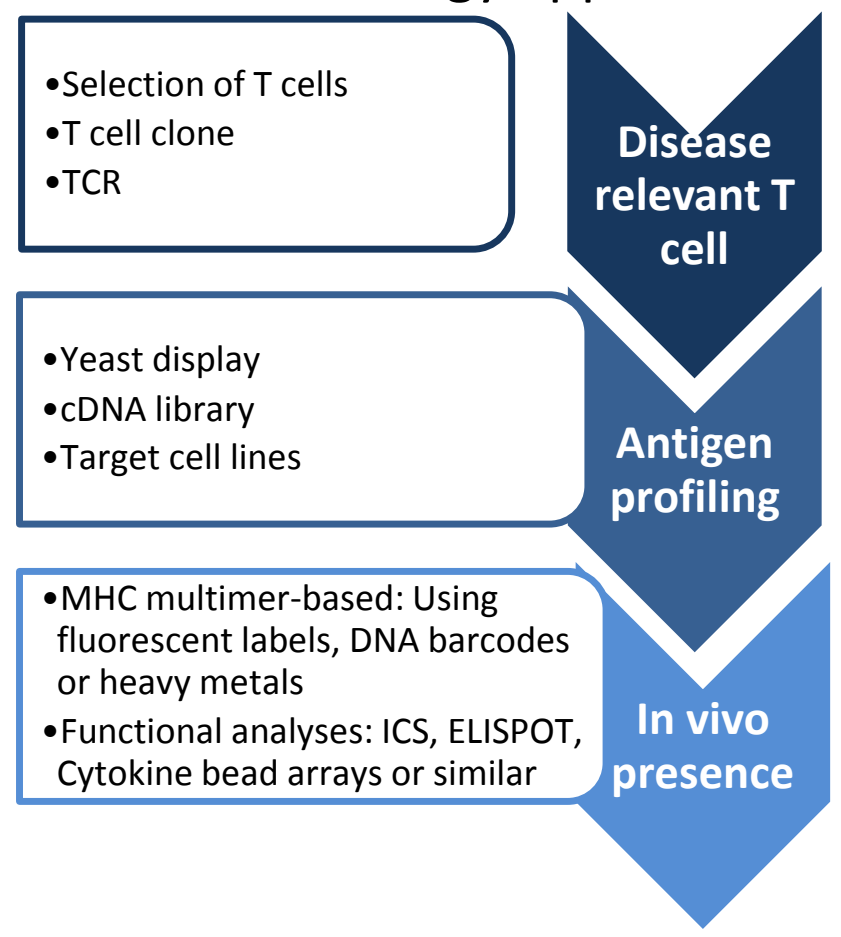

\section{'Indirect' immunology approach}

- Prior knowledge on disease

mechanism
-MS analyses of eluted peptides

-NGS data

Selection of
antigen

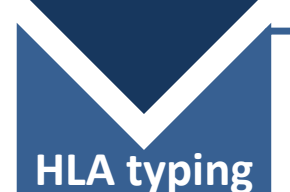

-NGS

- Flow Cytometry

-Personalized or HLA-stratification based selection

\section{$\&$ selection}

$\bullet \mathrm{MHC}$ multimer-based: Using

fluorescent labels, DNA barcodes or heavy metals

Screening

Strategy

- Functional analyses: ICS, ELISPOT, Cytokine bead arrays or similar
- Number of cells available

-Viability \& quality

- Location and tissue origin

selection

- Frequency of antigen specific T cells

- Functionality

-Phenotype

-Distribution and heterogeneity 
Figure 3: Moving towards $\mathrm{T}$ cell antigen recognition landscapes

Through the examination of $T$ cell recognition and the identification of antigen profiles of relevance one can gain insight to heterogeneity, functionality and phenotype of disease mediating $T$ cells. Such mechanistic knowledge opens new opportunities for disease interventions

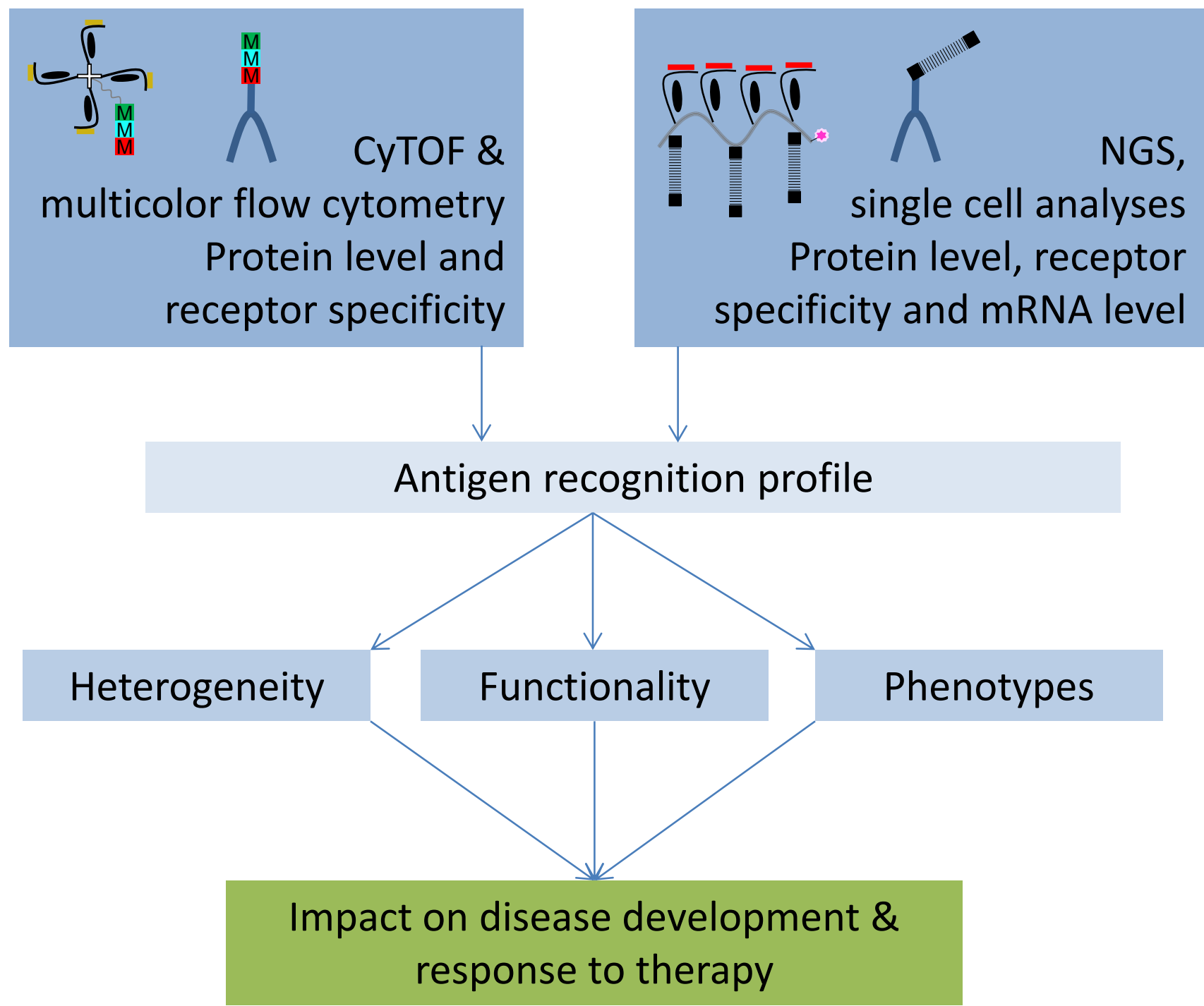




\section{Figure 4: Translation to therapeutic application.}

T cell recognition profiling may be applied before, during and after therapy to guide therapeutic decision making in immunotherapeutic strategies based on patient's immunocompentences and response to therapy. Immune analyses can advise the selection of patients tailored therapies and clinical decision making.

\section{Pre-therapy}

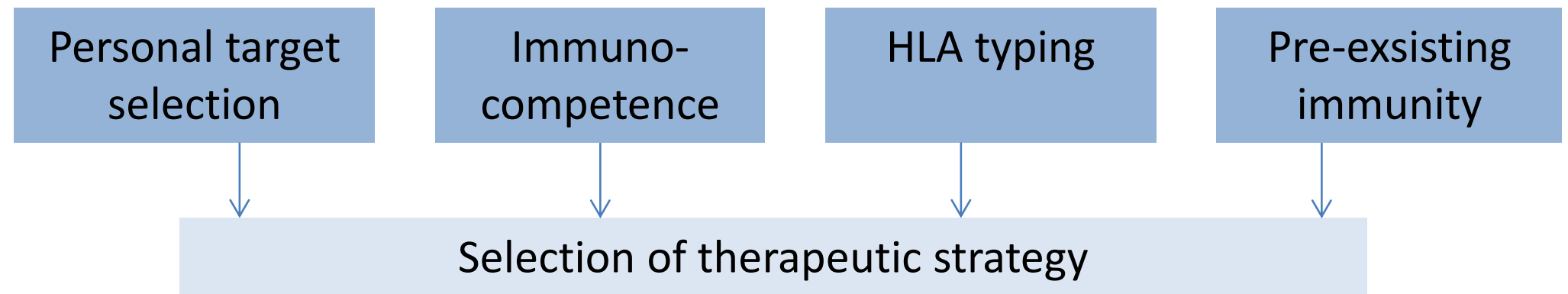

\section{Post-therapy}
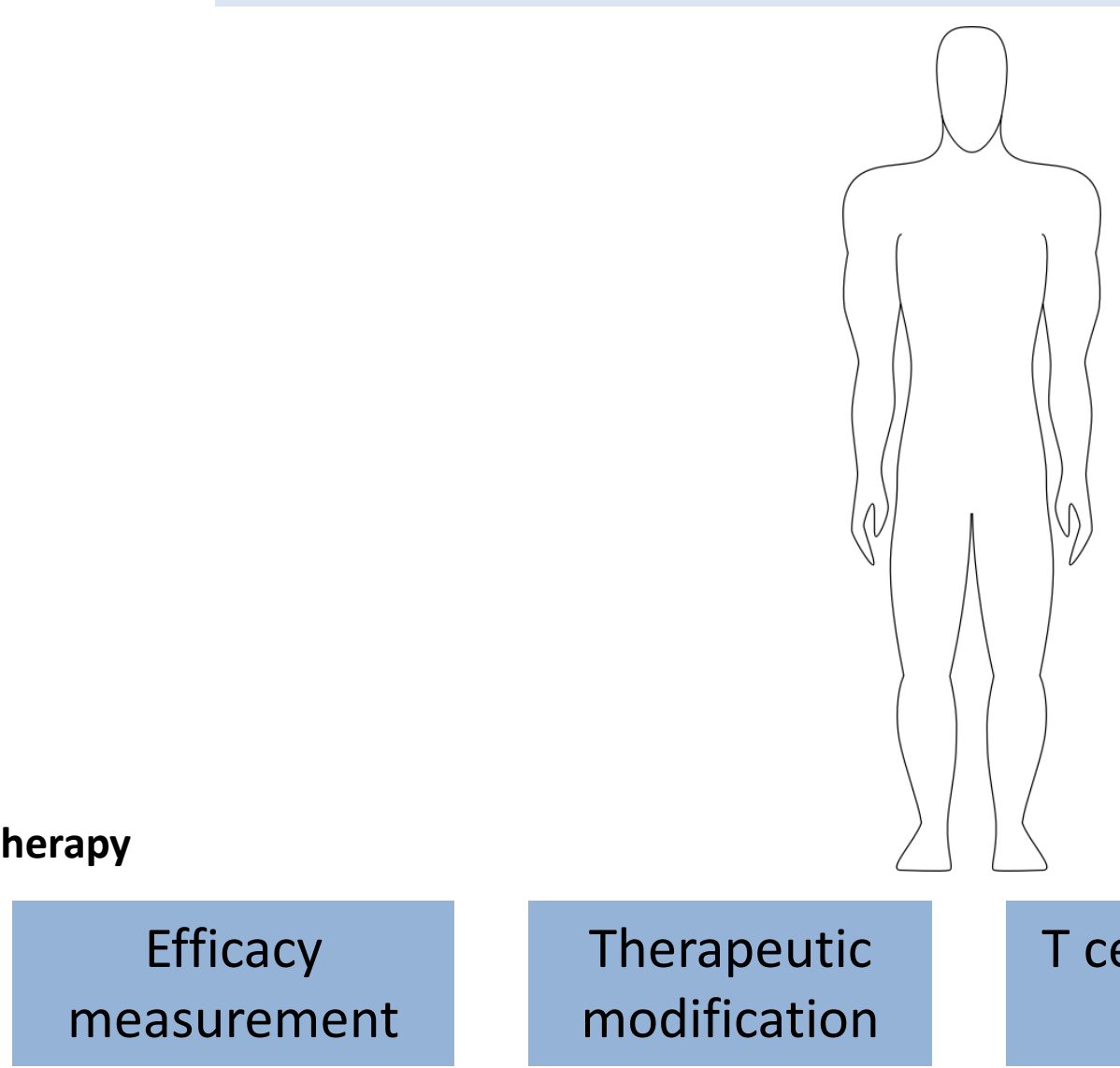